\title{
Adangme Language
}

National Cancer Institute

\section{Source}

National Cancer Institute. Adangme Language. NCI Thesaurus. Code C153826.

A Ghana-T ogo Mountain language of the Kwa family, spoken by the Adan and Agotime people of Ghana and Togo. 